\title{
The B/Sb diagonal relationship: Hydrostibination
}

Katherine M. Marczenko, ${ }^{\mathrm{a}, \mathrm{c}}$ Joseph A. Zurakowski, ${ }^{\mathrm{a}, \mathrm{c}}$ Karlee L. Bamford, ${ }^{\mathrm{b}}$ Josh MacMillan, ${ }^{\mathrm{a}}$ and Saurabh S. Chitnis*a

aDalhousie University, Department of Chemistry, 6274 Coburg Road, Halifax, Nova Scotia, Canada

bUniversity of Toronto, Department of Chemistry, 80 St. George Street, Toronto, Ontario, Canada

${ }^{\mathrm{C}}$ Equal contribution

Abstract: A rigid naphthalenediamine framework has been used to prepare antimony hydrides that feature LUMO shapes and energies strikingly similar to those of secondary boranes. Exploiting this feature, we report the first example of uncatalyzed hydrostibination of robust $\mathrm{C} \equiv \mathrm{C}, \mathrm{C}=\mathrm{C}, \mathrm{C}=\mathrm{O}$, and $\mathrm{N}=\mathrm{N}$ bonds as a new elementary hydrometallation reaction analogous to hydroboration. In the alkyne case, a $Z$-olefin is formed and in the reaction with $\mathrm{N}=\mathrm{N}$ bonds, hydrostibination and hydrogenation are both observed. These results endorse the notion of a diagonal relationship between the lightest $p$-block element and the heaviest Group 15 elements and may lead to the realization of novel reaction chemistry. 
Diagonal relationships between elements based on valency, electronegativity or frontier orbital similarity (isolobality) are a powerful organizing concept for predicting structure, bonding and reactivity in the main group elements. This notion is usually applied for element from adjacent periodic groups and principle quantum numbers $n$ and $n+1$, as shown by the comparative chemistry of $\mathrm{Li} / \mathrm{Mg}, \mathrm{Be} / \mathrm{Al}, \mathrm{B} / \mathrm{Si}, \mathrm{C} / \mathrm{P}$ element pairs. ${ }^{[1]}$

Recently we reported the synthesis and structure of bismuth and antimony triamides whose molecular and electronic structure was strongly reminiscent of boranes because each featured a neutral, planar, trivalent $p$-block element expressing a vacant $p$-orbital perpendicular to the molecular plane (compare Figure $1 a$ and $b$ ). ${ }^{[2]}$ Given that the Pauling electronegativity of boron (2.04), bismuth (2.02) and antimony (2.05) are also similar we were interested in exploring the nonintuitive diagonal relationship between the lightest p-block element and the heaviest group 15 elements. In this context it is also noteworthy that the LUMO of binary halides $\mathrm{SbX}_{3}$ and $\mathrm{BiX}_{3}$ ( $\mathrm{X}=\mathrm{F}, \mathrm{Cl}, \mathrm{Br}, \mathrm{I}$ ) under the $C_{3 v}$ point group is an equal sum of two $\mathrm{E}-\mathrm{X} \sigma^{*}$ orbitals that bears a striking resemblance to the vacant $\mathrm{p}$-orbital of boranes (Figure 1c). As a result, derivatives of $\mathrm{SbX}_{3}$ and $\mathrm{BiX}_{3}$ exhibit Lewis acidic behaviour towards a variety of ligands including multiple bonds ${ }^{[3]}$ and participate in metathesis chemistry to transfer anionic substituents to other element centres ${ }^{[4]}$ - both classical features of boranes. It is surprising, however, that another classical reaction of boranes - spontaneous and catalyst-free hydroboration (Figure 1d) - has no analogue in antimony and bismuth chemistry. In the case of bismuth, this is presumably due to the low kinetic stability of the hydrides, which has permitted the isolation of only a single example in the condensed phase,$^{[5]}$ precluding reactivity studies.

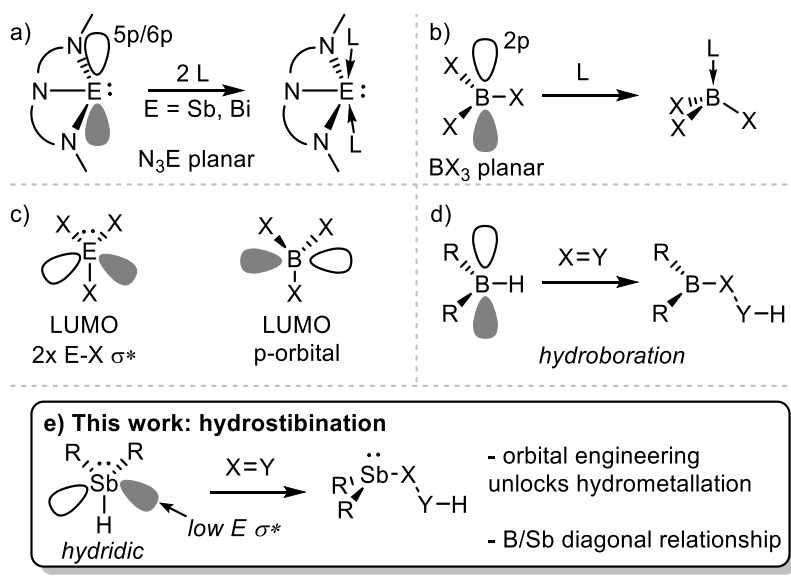

Figure 1. a) Recently reported planar antimony and bismuth triamides that show Lewis acidity perpendicular to the molecular plane. b) Lewis acidity perpendicular to the molecular plane in boranes. c) Similarity between LUMOs of Group 15 and Group 13 elements. d) Catalyst and additive free hydroboration. e) Catalyst and additive-free hydrostibination. 
On the other hand, antimony hydrides are (relatively) stable and several examples have been isolated, including a recent family of di(amino)stibines ${ }^{[6]}$ Previous work by Breunig ${ }^{[7]}$ and Huang ${ }^{[8]}$ showed overall hydrostibination of $\mathrm{C} \equiv \mathrm{C}$ and $\mathrm{C}=\mathrm{O}$ with diphenylstibine $\left(\mathrm{Ph}_{2} \mathrm{SbH}\right)$, but crucially this required mediation by radical initiators, transition metal catalysts, and/or main group Lewis acids. The intimate role of these additives was evident by i) chiral induction observed when enantiopure ligands were present in the additive, and ii) complete lack of reactivity in the absence of the additives. Nesmeyanov and Brandt also proposed hydrostibination of acetylene and azobenezene but this was based on ambiguous infrared and mass spectrometric data on reaction mixtures. ${ }^{[9]}$ Thus, to the best of our knowledge, catalyst and additive-free hydrostibination - a true analogue of hydroboration - remains to be definitively established. Indeed, the known reactivity of the Sb$\mathrm{H}$ bonds is comprised almost exclusively of $\mathrm{H}^{+}$or $\mathrm{H} \bullet$ transfer pathways, ${ }^{[6 e, 6 h, 10]}$ rather than hydride transfer.

We now report the straightforward synthesis of a new family of diaminostibines featuring a distorted naphthalene diamine skeleton, which demonstrate additive-free anti-Markovnikov hydrostibination of $\mathrm{C} \equiv \mathrm{C}, \mathrm{C}=\mathrm{C}, \mathrm{C}=\mathrm{O}$, and $\mathrm{N}=\mathrm{N}$ bonds (Figure $1 \mathrm{e}$ ). These results reveal a new main group hydrometallation reaction, endorse the emerging notion of a $\mathrm{B} / \mathrm{Sb}$ diagonal relationship, and may lead to new catalytic reactions complementary to those recently developed for $\mathrm{N}$ heterocyclic phosphine hydrides. ${ }^{[11]}$

We suspected that Breunig and Huang observed no hydrostibination under catalyst-free conditions with $\mathrm{Ph}_{2} \mathrm{SbH}$ because the LUMO of this stibine (-0.71 eV, PBE1/def2-TZVP level) was not sufficiently low to engage unsaturated substrates (c.f. LUMO in $\mathrm{Ph}_{2} \mathrm{BH}$ is at $-2.01 \mathrm{eV}$ ). The LUMO in $\mathrm{Ph}_{2} \mathrm{SbH}$ also shows extensive delocalization over the adjacent phenyl rings. Increasing the $\mathrm{Sb}-\mathrm{X}$ bond polarity by using electronegative amino substituents (Figure 2a) focuses the LUMO onto the metal centre and also makes it more electropositive (compare NBO partial charges in Figure 2). But it does not lower the LUMO energy due to nitrogen lone pair to $\mathrm{Sb}-\mathrm{N} \sigma^{*}$ backdonation, resulting in a high eigenvalue of $-0.42 \mathrm{eV}$ in $\left(\mathrm{Me}_{2} \mathrm{~N}\right)_{2} \mathrm{SbH}$. However, fusing the amino substituents with a rigid naphthalene backbone (Figure $2 \mathrm{~b}$ ) necessitates molecular distortion to fit the antimony atom within the $\mathrm{NC}_{3} \mathrm{~N}$ bay, causing the $\mathrm{N}$ lone pairs to twist away from the plane of the Sb-N $\sigma^{*}$ LUMO, lowering its energy dramatically to $-1.34 \mathrm{eV}$ while retaining its localization at $\mathrm{Sb}$. Addition of silyl groups to the amino substituents (Figure $2 \mathrm{c}$ ) was envisioned to provide steric protection against $\mathrm{H}_{2}$ loss $^{[5,6 b, 6 d, 6 g]}$ and activate the Sb-H bond via $\sigma(\mathrm{N}-\mathrm{Si})$ to $\sigma^{*}(\mathrm{Sb}-\mathrm{H})$ hyperconjugation made possible by the large $\left(167.2^{\circ}\right) \mathrm{H}-\mathrm{Sb}-\mathrm{N}-\mathrm{Si}$ dihedral angle ( $\beta$-silicon effect). ${ }^{[12]}$ Thus, when a naphthyl-silyl amino substituent is used i) the putative hydride is sterically shielded, ii) its LUMO is prominently centered at the metal, and iii) the LUMO energy is significantly lower $(-1.25 \mathrm{eV})$ than in $\mathrm{Ph}_{2} \mathrm{SbH}$. Collectively, these features foreshadowed the potential for facile 
binding with unsaturated substrates and subsequent hydride transfer. The pivotal role of geometric deformation is highlighted by the low electrophilicity of the LUMO $(-0.742 \mathrm{eV})$ in $((\mathrm{TMS}) \mathrm{PhN})_{2} \mathrm{SbH}$, which has two free amino groups instead of a fused naphthyl substituent.

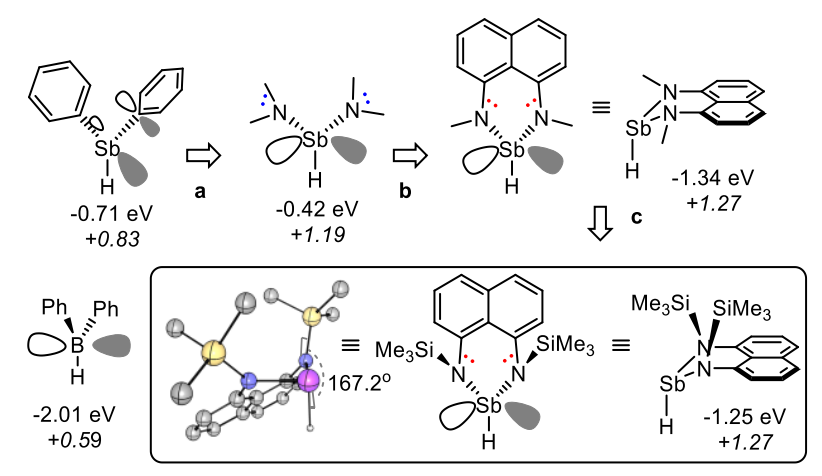

Figure 2. Major LUMO contributions, LUMO eigenvalues (eV), and NBO partial charges (italics) for $\mathrm{Sb}$ atoms in the considered stibines and $\mathrm{Ph}_{2} \mathrm{BH}$.

Lithiation of 1,8-naphthalene diamine in THF followed by quenching with an appropriate chlorosilane quantitatively yields amines 1a-c (Scheme 1a). A second bout of lithiation followed by quenching with $\mathrm{SbCl}_{3}$ yielded chlorostibines 2a-c in 52-69\% yields as highly air-sensitive yellow crystals. ${ }^{[13]}$ The solid-state structures of $2 \mathrm{a}-\mathbf{c}$ were established using X-ray crystallography (Figure 3 and Figure S1). Each derivative features a three-coordinate pyramidal antimony centre coordinated to a bidentate ligand and a chloride atom. The structural aspects of the chlorostibines do not vary significantly and are therefore not discussed at length.

Addition of the chlorostibines as hexane solutions to a suspension of $\mathrm{LiHBEt}_{3}$ in hexane/thf at $-30{ }^{\circ} \mathrm{C}$, a protocol adapted from the work of Dostàl and Coles, ${ }^{[6 a, 14]}$ yielded antimony hydrides $3 \mathbf{3 a}-$ c. These reactions proceeded in reasonable isolated yield for $\mathbf{3 b}(77 \%)$ and $\mathbf{3 c}(58 \%)$ but $\mathbf{3 a}$ proved to be a thermally unstable oil, which could only be spectroscopically characterized in freshly made solutions before extensive decomposition occurred denoted by loss of metallic $\mathrm{Sb}$. Two attempts were made to obtain single crystals of $3 a$ by rigorous cryogenic handling $\left(-25^{\circ} \mathrm{C}\right.$ throughout) but in both cases only a few crystals of the distibine 4 were isolated (Figure S2), suggesting dehydrogenative coupling ${ }^{[6 b, 6]}$ is at least partly responsible for the observed thermal instability of this compound (Scheme $\mathbf{1 b}$ ). In contrast, hydrides $\mathbf{3 b}$ and $\mathbf{3 c}$ are air-sensitive but indefinitely stable under an inert atmosphere of dry and deoxygenated nitrogen in the solid phase and in non-halogenated solvents. They are not sensitive to ambient light but slowly eliminate $\mathbf{1 b}$ and 1c, as well as metallic Sb, upon heating above $50{ }^{\circ} \mathrm{C}$ (Scheme 1c). The solid-state structure of $3 c$ could be established crystallographically (Figure 3 ) with electron density found within the difference map being consistent with the expected location of hydride. The three-coordinate antimony center has a pyramidal geometry with approximately equivalent $\mathrm{Sb}-\mathrm{N}$ bond lengths. The 
structure of $\mathbf{3 b}$ was also determined crystallographically (Figure S3) but although the heavy atom positions are accurate, the hydride could not be located in the difference map.

a)
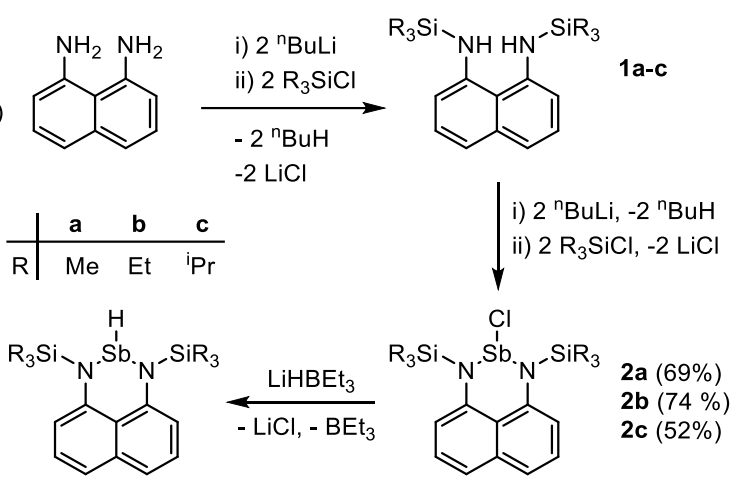

3a (in situ detection)

3b $(77 \%)$, 3c $(58 \%)$

b) $3 a \stackrel{\text { r.t. }}{\longrightarrow} \underset{-\mathrm{H}_{2}}{\longrightarrow}$

c) $3 b / 3 c \frac{50^{\circ} \mathrm{C}, 24 \mathrm{~h}}{-\mathrm{Sb}^{0}} 1 \mathrm{~b} / 1 \mathrm{c}$

Scheme 1. a) Synthesis of compounds 1, 2, and 3. b) Decomposition of 3a to give 4. c) Thermal decomposition of $\mathbf{3 b}$ and $\mathbf{3 c}$.
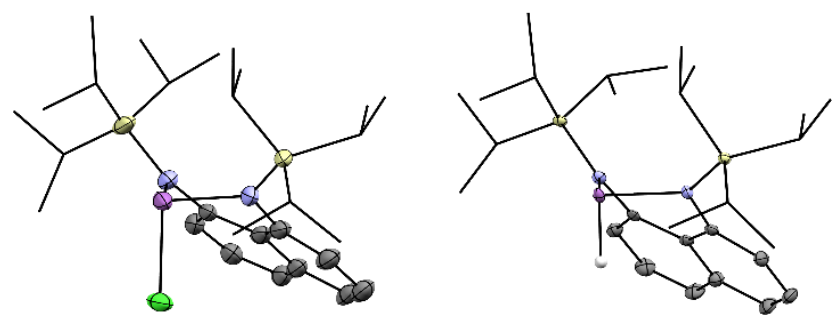

Figure 3. Molecular structures of 2c (left) and 3c (right) in the solid state as determined by X-ray crystallography. Thermal ellipsoids are drawn at the $50 \%$ probability level. The carbon atoms of the isopropyl groups are shown in wireframe for clarity. Nonessential hydrogen atoms have been omitted.

The ${ }^{1} \mathrm{H}$ NMR spectra of the stibines in $\mathrm{C}_{6} \mathrm{D}_{6}$ show sharp resonances for the Sb-H fragment with chemical shifts that increase with the steric bulk of the N-silyl group (9.65 ppm for $\mathbf{3 a}, 9.88$ ppm for $\mathbf{3 b}$, and $10.04 \mathrm{ppm}$ for $\mathbf{3 c}$ ). These values are close to those established for diaminostibines, ${ }^{[6 a]}$ but several ppm downfield from resonances reported for diarylstibines. Infrared spectroscopy revealed Sb-H stretching frequencies of $1883 \mathrm{~cm}^{-1}$ and $1863 \mathrm{~cm}-1$ for $3 \mathrm{~b}$ and $3 c$, respectively. High resolution mass spectrometry showed the masses expected for the 
$[\mathrm{M}+1]^{+}$ions corresponding to the ${ }^{121} \mathrm{Sb}(57 \%)$ and ${ }^{123} \mathrm{Sb}(43 \%)$ isotopomers for all except $3 \mathrm{a}$ for which only the free ligand was observed due to decomposition within the spectrometer.

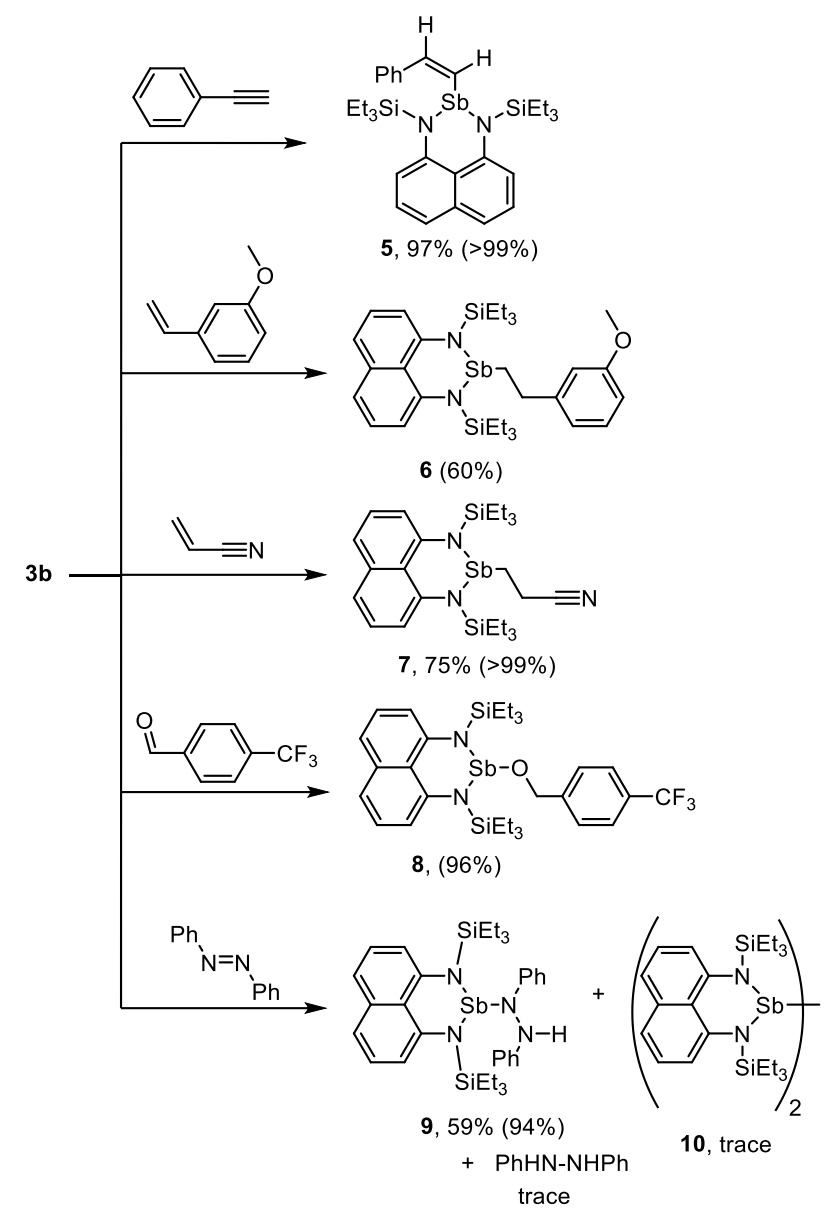

Scheme 2. Hydrostibination reactivity of $\mathbf{3 b}$. Yields are for isolated materials. Yields in parentheses were determined from NMR spectroscopy.

As a compromise between synthetic yield of the hydride and cost of the chlorosilane, $\mathbf{3 b}$ was chosen to test hydrostibination reactivity. For computational efficiency it was convenient to use 3a for DFT calculations. The LUMO of this model compound is shown in Figure S4, evidencing its p-orbital like character and orthogonality to the $\mathrm{Sb}-\mathrm{H}$ bond. To assess whether the $\mathrm{Sb}-\mathrm{H}$ bond was hydridic, $3 \mathbf{b}$ was combined with $\mathrm{Ph}_{3} \mathrm{CB}\left(\mathrm{C}_{6} \mathrm{~F}_{5}\right)_{4}$. The ${ }^{1} \mathrm{H}$ NMR spectrum of this reaction showed disappearance of the distinctive $\mathrm{Sb}-\mathrm{H}$ resonance and appearance of resonances due to $\mathrm{Ph}_{3} \mathrm{CH}$ (Figure S5). The diaminostibenium byproduct was not isolated as such species are already wellknown ${ }^{[13 a, 13 b, 15]}$ and the $\mathrm{Ph}_{3} \mathrm{CH}$ formation adequately demonstrates $\mathrm{H}^{-}$transfer from $\mathbf{3 b}$ proving its hydridicity.

Addition of freshly distilled phenylacetylene to $3 \mathbf{b}$ in $\mathrm{C}_{6} \mathrm{D}_{6}$ at room temperature and monitoring the reaction mixture by NMR spectroscopy revealed quantitative consumption of the $\mathrm{Sb}-\mathrm{H}$ and acetylene resonances over 24 hours. Upon completion, the ${ }^{1} \mathrm{H}$ NMR spectrum of the crude 
reaction mixture indicated formation of a single product having two olefinic resonances at 6.32 ppm and 7.07 ppm of equal intensity $\left({ }^{3} \mathrm{~J}_{\mathrm{HH}}=12.4 \mathrm{~Hz}\right)$ and the ${ }^{13} \mathrm{C}$ NMR spectrum showed eight $\mathrm{C}_{\mathrm{sp} 2}-\mathrm{H}$ resonances. Together with the high-resolution mass spectrum of the reaction mixture, which showed peaks at $609.2068 \mathrm{amu}$ and $611.2072 \mathrm{amu}$ for the ${ }^{121} \mathrm{Sb}$ and ${ }^{123} \mathrm{Sb}$ containing isotopomers, the formation of a single anti-Markovnikov hydrostibination product, $\mathbf{5}$, could be inferred. A two-dimensional NOESY experiment indicated spatial proximity of the olefinic resonances and single crystal $X$-ray diffraction unambiguously confirmed that the $Z$ isomer had formed (Figure 4).

DFT calculations using model compound $\mathbf{3 a}$ indicate that formation of the $E$ olefin is marginally favoured $\left(\Delta G_{r x n}=-32.2 \mathrm{kcal} \mathrm{mol}^{-1}\right)$ over the $Z$ olefin $\left(\Delta G_{r x n}=-29.9 \mathrm{kcal} \mathrm{mol}^{-1}\right)$, and we therefore believe that exclusive detection of the latter isomer is a signature of the hydrostibination mechanism rather than a result of isomer equilibriation. This, in turn, is consistent with a stepwise mechanism involving a vinyl carbocation intermediate that undergoes anti hydride addition, rather than the concerted syn hydride addition that is canonical for alkyne hydroboration. This reactive vinyl cation apparently requires resonance stabilization from an adjacent phenyl ring ${ }^{[16]}$ given that no reaction was observed when terminal alkynes with inductively donating substituents but lacking $\pi$-electrons (1-octyne and trimethylsilyl acetylene) were used as substrates. No intermediates were detected by NMR spectroscopy during the reaction, and resonances for $\mathbf{3 b}$ and phenylacetylene do not exhibit broadening or chemical shift change upon mixing, implying a low concentration of any ionic intermediate.

A radical mechanism is unlikely given that i) the reaction is not retarded when conducted in the dark and ii) Breunig reported formation of the E-olefin in AIBN mediated addition of $\mathrm{Ph}_{2} \mathrm{SbH}$ to phenylacetylene. ${ }^{[7]} \mathrm{A}$ mechanism involving protonation of phenylacetylene by $\mathbf{3} \mathbf{b}$ followed by diaminostibinide attack would be inconsistent with the anti-Markovnikov selectivity and the hydridic nature of the $\mathrm{Sb}-\mathrm{H}$ bond in this stibine.
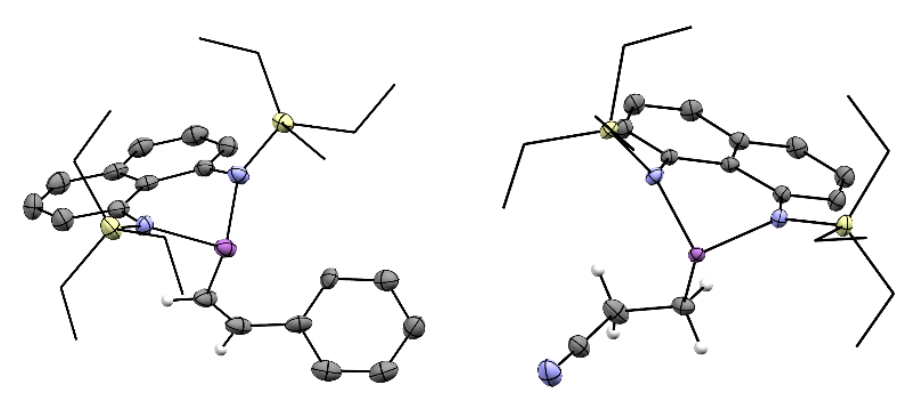

Figure 4. Molecular structures of 5 (left) and $\mathbf{7}$ (right) in the solid state as determined by X-ray crystallography. Thermal ellipsoids are drawn at the 50\% probability level. Nonessential hydrogen atoms have been omitted. 
Hydrostibination of electron-rich and electron-poor alkenes was also achieved. Addition of distilled 3-vinylanisole to $\mathbf{3 b}$ yielded the alkane 6 but the reaction was sluggish, requiring 5 days to reach ca. $60 \%$ conversion at ambient temperature. Over this period, some background decomposition of $\mathbf{3} \mathbf{b}$ was also noted both spectroscopically $\left({ }^{1} \mathrm{H}\right.$ NMR resonances for $\left.\mathbf{2} \mathbf{b}\right)$ and visually (formation of metallic $\mathrm{Sb}$ ). The ${ }^{1} \mathrm{H}$ NMR spectrum of the reaction mixture showed two new methylene resonances indicating anti-Markovnikov addition across the alkene (Figure S20). The expected molecular ions corresponding to the ${ }^{121} \mathrm{Sb}$ and ${ }^{123} \mathrm{Sb}$ isotopologues of 6 were detected by high-resolution mass spectrometry. Isolation of this compound from the partially converted mixture was not pursued, but the spectroscopic data are fully consistent with its identity. In contrast, the reaction of $\mathbf{3 b}$ with neat distilled acrylonitrile proceeded quantitatively within $24 \mathrm{~h}$ and yielded 7 , which could be isolated by removal of the excess alkene under vacuum. The ${ }^{1} \mathrm{H}$ and two-dimensional COSY NMR spectra for this compound indicate anti-Markovnikov addition and this was corroborated by X-ray crystallography (Figure 4). Interestingly, the extended structure shows intermolecular $\mathrm{Sb}---\mathrm{N} \equiv \mathrm{C}-\mathrm{R}$ interactions that form a dimer, indicating a degree of unquenched Lewis acidity at the antimony centre in 7 . No addition to the $C \equiv N$ triple bond was observed under these conditions.

No reaction was detected between $\mathbf{3 b}$ and benzaldehyde or $p$-anisaldehyde over $24 \mathrm{~h}$ at ambient temperature. In contrast, when $\mathbf{3} \mathbf{b}$ was added to freshly distilled excess $p$-trifluoromethyl benzaldehyde in hexane smooth conversion to alkoxy stibine 8 was observed in $96 \%$ spectroscopic yield. Complete separation of the product from the excess aldehyde (viscous oil) proved futile but the identity of $\mathbf{8}$ was confirmed by high-resolution mass spectrometry and appearance of a diagnostic methylene resonance at $4.48 \mathrm{ppm}$ in the ${ }^{1} \mathrm{H}$ NMR spectrum. DFT calculations indicate that hydrostibination is thermodynamically favourable for both $p$ anisaldehyde $\left(\Delta \mathrm{G}_{\mathrm{rxn}}=-10.1 \mathrm{kcal} \mathrm{mol}^{-1}\right)$ and $p$-trifluoromethyl benzaldehyde $\left(\Delta \mathrm{G}_{\mathrm{rxn}}=-14.8 \mathrm{kcal} \mathrm{mol}^{-}\right.$ $\left.{ }^{1}\right)$. The lack of a reaction involving the electron-rich substrates is therefore viewed as a kinetic obstacle, which suggests that the aldehyde acts as an electrophile in the rate-limiting step. Since no intermediates were detected over the course of the reaction by NMR spectroscopy and no broadening or chemical shift change was observed upon mixing the reagents, we propose the formation of an endothermic adduct via Sb---O interactions followed by slow hydride transfer to the benzyllic carbon to furnish the final product. The endothermicity of adduct formation would explain the inability to detect an intermediate.

Addition of $\mathbf{3 b}$ to trans-azobenzene in $\mathrm{C}_{6} \mathrm{D}_{6}$ resulted in formation of $\mathbf{9}$ in $94 \%$ spectroscopic yield, as indicated by appearance of a new N-H resonance at $5.02 \mathrm{ppm}$ in the ${ }^{1} \mathrm{H}$ NMR spectrum and detection of an N-H stretch by infrared spectroscopy at $3353 \mathrm{~cm}^{-1}$. High-resolution mass spectrometry yielded the correct masses for the $[\mathrm{M}+1]^{+}$isotopomers of 9 ( ${ }^{121} \mathrm{Sb}: 689.2474 \mathrm{amu}$, ${ }^{123} \mathrm{Sb}$ : $691.2450 \mathrm{amu}$ ) and its structure was further confirmed by X-ray crystallography (Figure 5). 
Interestingly, this reaction also gave a small amount of diphenylhydrazine in $6 \%$ spectroscopic yield indicating hydrogenation rather than hydrostibination of azobenzene, which requires reduction of the $\mathrm{Sb}$ (III) centres. Careful examination of the reaction products under a microscope enabled us to select a few crystals that were subsequently identified by diffraction as the $\mathrm{Sb}-\mathrm{Sb}$ bonded species 10 , which contains the requisite $\mathrm{Sb}(\mathrm{II})$ centres, thus fully accounting for the observed redox chemistry (Figure 5). The most noteworthy feature in the molecular structure of 10 is the exceptionally long Sb-Sb bond length [2.9318(4) $\AA$ ], which is the second longest for neutral $\mathrm{Sb}_{2} \mathrm{X}_{4}$ derivatives. These results show that $\mathbf{3 b}$ can act not only as a hydride source but also an $\mathrm{H}$-atom source when a suitable substrate is present. A primary stibine $p$-tolylSbH $\mathrm{S}_{2}$ has previously been reported to hydrogenate styrene to ethylbenzene with elimination of ( $p$-tolylSb $)_{4}$ product. No change in the ratio of the hydrogenation product to the hydrostibination product was observed when the reaction was repeated in the dark or when the order of addition was reversed.
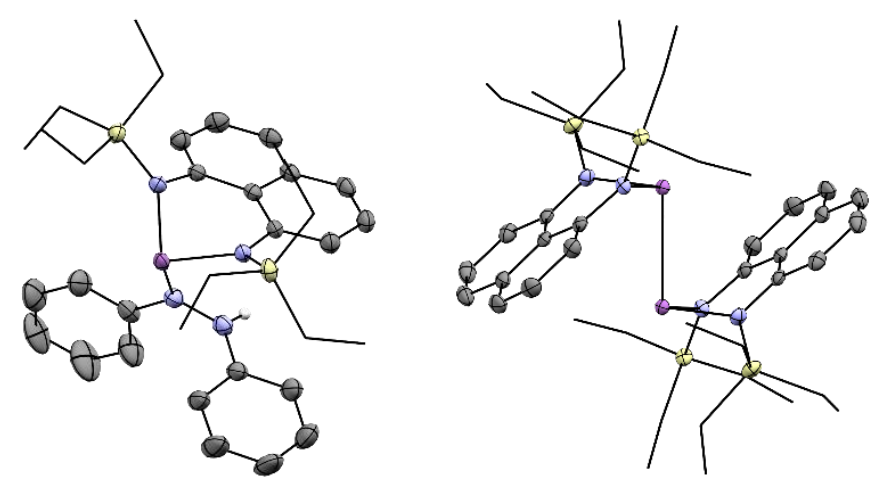

Figure 5. Molecular structures of 9 (left) and 10 (right) in the solid state as determined by X-ray crystallography. Thermal ellipsoids are drawn at the 50\% probability level. Nonessential hydrogen atoms have been omitted.

In summary, we reported a new class of antimony hydrides which participate in the first example of additive-free hydrostibination of $\mathrm{C} \equiv \mathrm{C}, \mathrm{C}=\mathrm{C}, \mathrm{C}=\mathrm{O}$, and $\mathrm{N}=\mathrm{N}$ bonds under ambient conditions as a direct analogue of hydroboration. This new hydrometallation reaction is unlocked by frontier orbital engineering through judicious ligand choice and offers a mild way of making $\mathrm{Sb}-\mathrm{C} / \mathrm{O} / \mathrm{N}$ bonds in high yields with anti-Markovnikov selectivity. Our findings reinforce the nonintuitive concept of a diagonal relationship between the lightest $p$-block element and the heaviest group 15 elements. As shown by hydrostibination of phenylacetylene, it is possible to realize reactivity that is orthogonal to hydroboration, which exclusively yields E-olefins from alkynes. Notably, the reactivity of $\mathbf{3 b}$ is also complementary to that of $\mathrm{N}$-heterocyclic phosphine hydrides, which do not hydrophosphinate alkynes and alkenes. ${ }^{[11 b-e]}$ Future studies will uncover mechanistic details and couple hydrostibination with reduction of the newly formed Sb-E bond to realize 
catalytic reductions, advancing our program of developing p-block element-based platforms for applications in synthetic chemistry.

\section{Experimental Section}

Synthetic details and characterization data are given in the Electronic Supporting Information.

\section{Acknowledgements}

We acknowledge the Natural Sciences and Engineering Resesarch Council (NSERC) of Canada, the Canada Foundation for Innovation (CFI), the Nova Scotia Research and Innovation Trust (NSRIT), and Dalhousie University for research funding. K.M.M. acknowledges the Vanier Canada Graduate Scholarships Program and the Walter C. Sumner Memorial Fellowships Program for funding. J. A. Z. acknowledges the Inorganic Chemistry Exchange (ICE) program. K. L. B. acknowledges NSERC for a graduate fellowship. J. M. acknowledges the Sobey Foundation for a summer research award. We acknowledge the CFI and Research Nova Scotia Trust for supporting the X-ray diffraction facility. We acknowledge colleagues in the Chemisry department at Dalhousie University for donating some of the chemicals used in this study. 


\section{References}

[1] a) A. Paparo, C. D. Smith, C. Jones, Angew. Chem. Int. Ed. 2019, 58, 11459-11463; b) K. B. Dillon, F. Mathey, J. F. Nixon, 1998; c) in Chemistry of the Elements (Second Edition) (Eds.: N. N. Greenwood, A. Earnshaw), Butterworth-Heinemann, Oxford, 1997, pp. 20-31.

[2] a) M. B. Kindervater, K. M. Marczenko, U. Werner-Zwanziger, S. S. Chitnis, Angew. Chem. Int. Ed. 2019, 58, 7850-7855; b) K. M. Marczenko, J. A. Zurakowski, M. B. Kindervater, S. Jee, T. Hynes, N. Roberts, S. Park, U. Werner-Zwanziger, M. LUMSDEN, D. N. Langelaan, S. S. Chitnis, Chemrxiv 2019.

[3] a) W. Levason, S. Maheshwari, R. Ratnani, G. Reid, M. Webster, W. Zhang, Inorg. Chem. 2010, 49, 9036-9048; b) W. Levason, M. E. Light, S. Maheshwari, G. Reid, W. Zhang, Dalton Trans. 2011, 40, 5291-5297; c) S. L. Benjamin, W. Levason, G. Reid, M. C. Rogers, R. P. Warr, J. Organomet. Chem. 2012, 708, 106-111; d) S. S. Chitnis, N. Burford, R. McDonald, M. J. Ferguson, Inorg. Chem. 2014, 53, 5359-5372; e) H. Schmidbaur, A. Schier, Organometallics 2008, 27, 2361-2395.

[4] a) Y. Matano, in Chapter 6 Ligand coupling involving organobismuth compounds: Tetrahedron Organic Chemistry Series, Vol. Volume 18 (Ed.: F. Jean-Pierre), Elsevier, 1998, pp. 159-204; b) Y. Matano, in Pentavalent Organobismuth Reagents in Organic Synthesis: Bismuth-Mediated Organic Reactions (Ed.: T. Ollevier), Springer Berlin Heidelberg, Berlin, Heidelberg, 2012, pp. 19-44.

[5] N. J. Hardman, B. Twamley, P. P. Power, Angew. Chem. Int. Ed. 2000, 39, 2771-2773.

[6] a) R. J. Schwamm, A. J. Edwards, C. M. Fitchett, M. P. Coles, Dalton Trans. 2019, 48, 2953-2958; b) D. G. Hendershot, A. D. Berry, J. Organomet. Chem. 1993, 449, 119-123; c) B. Twamley, C.-S. Hwang, N. J. Hardman, P. P. Power, J. Organomet. Chem. 2000, 609, 152-160; d) R. J. Baker, M. Brym, C. Jones, M. Waugh, J. Organomet. Chem. 2004, 689, 781-790; e) R. Waterman, T. D. Tilley, Angew. Chem. Int. Ed. 2006, 45, 2926-2929; f) H. J. Breunig, E. Lork, O. Moldovan, C. I. Rat, J. Organomet. Chem. 2008, 693, 25272534; g) G. Balazs, H. Breunig, E. Lork, W. Offermann, ORGANOMETALLICS 2001, 20, 2666-2668; h) C. Marquardt, O. Hegen, M. Hautmann, G. Balázs, M. Bodensteiner, A. V. Virovets, A. Y. Timoshkin, M. Scheer, Angew. Chem. Int. Ed. 2015, 54, 13122-13125.

[7] H. J. Breunig, J. Probst, J. Organomet. Chem. 1998, 571, 297-303.

[8] Y. Huang, Y. Shen, C. Chen, Tetrahedron Lett. 1985, 26, 5171-5172.

[9] a) A. N. Nesmeyanov, A. E. Borisov, N. V. Novikova, Bulletin of the Academy of Sciences of the USSR, Division of chemical science 1965, 14, 749-749; b) K.-H. Linke, W. Brandt, Z. Anorg. Allg. Chem. 1977, 433, 119-132.

[10] a) H. Breunig, M. Ghesner, E. Lork, Z. Anorg. Allg. Chem. 2005, 631, 851-856; b) R. Waterman, T. D. Tilley, Inorg. Chem. 2006, 45, 9625-9627; c) G. Balázs, M. Sierka, M. 
Scheer, Angew. Chem. Int. Ed. 2005, 44, 4920-4924; d) K. Issleib, A. Balszuweit, Z. Anorg. Allg. Chem. 1976, 419, 87-91.

[11] a) C. C. Chong, H. Hirao, R. Kinjo, Angew. Chem. Int. Ed. 2014, 53, 3342-3346; b) M. R. Adams, C. H. Tien, B. S. N. Huchenski, M. J. Ferguson, A. W. H. Speed, Angew. Chem. Int. Ed. 2017, 56, 6268-6271; c) C.-H. Tien, M. R. Adams, M. J. Ferguson, E. R. Johnson, A. W. H. Speed, Org. Lett. 2017, 19, 5565-5568; d) T. Hynes, E. N. Welsh, R. McDonald, M. J. Ferguson, A. W. H. Speed, Organometallics 2018, 37, 841-844; e) D. Gudat, Dalton Trans. 2016, 45, 5896-5907.

[12] a) J. B. Lambert, G. T. Wang, R. B. Finzel, D. H. Teramura, J. Am. Chem. Soc. 1987, 109, 7838-7845; b) N. Kramer, C. Jöst, A. Mackenroth, L. Greb, Chem. Eur. J. 2017, 23, 17764-17774.

[13] a) H. A. Spinney, I. Korobkov, D. S. Richeson, Chem. Commun. 2007, 1647-1649; b) H. A. Spinney, I. Korobkov, G. A. DiLabio, G. P. A. Yap, D. S. Richeson, Organometallics 2007, 26, 4972-4982; c) K. Dzialkowski, A. Gehlhaar, C. Wölper, A. A. Auer, S. Schulz, Organometallics 2019, 38, 2927-2942.

[14] P. Šimon, F. de Proft, R. Jambor, A. Růžička, L. Dostál, Angew. Chem. Int. Ed. 2010, 49, 5468-5471.

[15] a) C. Hering, M. Lehrnann, A. Schulz, A. Villinger, Inorg. Chem. 2012, 51, 8212-8224; b) M. Lehmann, A. Schulz, A. Villinger, Angew. Chem. Int. Ed. 2012, 51, 8087-8091.

[16] a) P. J. Stang, Z. V. I. Rappoport, M. Hanack, L. R. Subramanian, in Vinyl Cations (Eds.: P. J. Stang, Z. V. I. Rappoport, M. Hanack, L. R. Subramanian), Academic Press, 1979, pp. 290-447; b) T. Müller, R. Meyer, D. Lennartz, H.-U. Siehl, Angew. Chem. Int. Ed. 2000, 39, 3074-3077; c) T. Müller, M. Juhasz, C. A. Reed, Angew. Chem. Int. Ed. 2004, 43, 1543-1546. 